\title{
Effectiveness of individualized physiotherapy on pain and functioning compared to a standard exercise protocol in patients presenting with clinical signs of subacromial impingement syndrome. A randomized controlled trial
}

Thilo O Kromer*1,3, Rob A de Bie 2,3,4 and Caroline HG Bastiaenen2,3,4

\begin{abstract}
Background: Shoulder impingement syndrome is a common musculoskeletal complaint leading to significant reduction of health and disability. Physiotherapy is often the first choice of treatment although its effectiveness is still under debate. Systematic reviews in this field highlight the need for more high quality trials to investigate the effectiveness of physiotherapy interventions in patients with subacromial impingement syndrome.

Methods/Design: This randomized controlled trial will investigate the effectiveness of individualized physiotherapy in patients presenting with clinical signs and symptoms of subacromial impingement, involving 90 participants aged 1875. Participants are recruited from outpatient physiotherapy clinics, general practitioners, and orthopaedic surgeons in Germany. Eligible participants will be randomly allocated to either individualized physiotherapy or to a standard exercise protocol using central randomization.

The control group will perform the standard exercise protocol aiming to restore muscular deficits in strength, mobility, and coordination of the rotator cuff and the shoulder girdle muscles to unload the subacromial space during active movements. Participants of the intervention group will perform the standard exercise protocol as a home program, and will additionally be treated with individualized physiotherapy based on clinical examination results, and guided by a decision tree. After the intervention phase both groups will continue their home program for another 7 weeks.

Outcome will be measured at 5 weeks and at 3 and 12 months after inclusion using the shoulder pain and disability index and patients' global impression of change, the generic patient-specific scale, the average weekly pain score, and patient satisfaction with treatment. Additionally, the fear avoidance beliefs questionnaire, the pain catastrophizing scale, and patients' expectancies of treatment effect are assessed. Participants' adherence to the protocol, use of additional treatments for the shoulder, direct and indirect costs, and sick leave due to shoulder complaints will be recorded in a shoulder log-book.
\end{abstract}

Discussion: To our knowledge this is the first trial comparing individualized physiotherapy based on a defined decision making process to a standardized exercise protocol. Using high-quality methodologies, this trial will add evidence to the limited body of knowledge about the effect of physiotherapy in patients with SIS.

Trial registration: Current Controlled Trials ISRCTN86900354

\footnotetext{
* Correspondence: Thilo.Kromer@epid.unimaas.nl

1 Physiotherapiezentrum, Grube 21, 82377 Penzberg, Germany

Full list of author information is available at the end of the article
}

๑ 2010 Kromer et al; licensee BioMed Central Ltd. This is an Open Access article distributed under the terms of the Creative Commons B. Wed Central Attribution License (http://creativecommons.org/licenses/by/2.0), which permits unrestricted use, distribution, and reproduction in any medium, provided the original work is properly cited. 


\section{Background}

Shoulder complaints are one of the most common musculoskeletal complaints seen by health professionals [1-5] with an incidence of 9.5 per 1000 patients presenting to primary care [6] and varying data for point prevalence (6.9\% to 26\%) [7]. They can lead to a significant reduction of health $[6,8]$, seem to be recurring in nature and do not necessarily resolve over time [9-12]. Thus, shoulder complaints represent a relevant health problem for clinicians, employers and health insurance companies.

Although no standardized diagnostic classification for shoulder complaints exists, most shoulder patients presenting to primary care show clinical signs of subacromial impingement $[5,6]$. Subacromial impingement syndrome of the shoulder (SIS) occurs due to a mechanical disturbance within the subacromial space and is characterized by pain and functional restrictions mostly during overhead activities in daily life or sporting activities [13]. Potential factors causing or contributing to SIS such as strength, coordination and integrity of the rotator cuff [14-21] and the shoulder girdle muscles [22-26], mechanical or anatomical changes [27-29], hypomobility or instability of the glenohumeral joint or the scapula [16,26,30$33]$, and the influence of posture [34,35] are discussed in the literature and suggest a multi-factorial aetiology of SIS. Besides the biomedical aspects of SIS, psychological factors such as kinesiophobia or catastrophizing may negatively influence recovery and thus leading to chronic pain and disability [36-41]. The specific diagnosis of SIS is often based on a thorough history and clinical examination; technical examination methods such as MRI or ultrasonography are often not used in first instance [10], also because their diagnostic accuracy is still limited [4247].

Physiotherapy is often the first choice of treatment for SIS. Between 10 to $30 \%$ of all shoulder patients seen in primary care are referred to physiotherapy after initial presentation $[5,10,48]$. However, the effectiveness of physiotherapy in patients with SIS is still under debate. Conclusions from systematic reviews suggest that physiotherapy-led interventions, combining different methods or techniques, are not more effective than exercises alone except adding manual mobilization to exercises, which seems to be of additional benefit. Most technical treatments such as ultrasound or laser therapy cannot be recommended. However evidence is limited by poor methodological quality, short follow ups and small sample sizes [49-52]. Thus nearly all current systematic reviews emphasize the need for more high quality trials of physiotherapy interventions, especially of combination of treatment techniques.

This trial compares individualized physiotherapy (IP), considering the patients' individual situation, bio-psychosocial aspects, and the WHO-classification of function- ing and disability [53] to a standardized exercise protocol (SEP). Physiotherapeutic management is based on clinical examination results and guided by a defined clinical reasoning process, which belongs to one of the basic skills in musculoskeletal physiotherapy [54].

\section{Aims of the study}

a) To investigate the effect of individually planned physiotherapy (IP) on pain and functioning compared to a standard exercise protocol (SEP) in patients presenting with clinical signs of SIS.

b) To compare direct and indirect costs between both interventions.

\section{Methods \\ Study design}

To answer the questions a randomized controlled trial design will be used over a 12 months period. Patients will be randomized after providing informed consent. Randomization and all communication about it is executed and controlled by the Department of Epidemiology, Maastricht University. A flow chart of the trial profile is provided in Figure 1.

\section{Ethics}

Ethical approval for this trial has been granted by the Medical Ethics Committee of the Munich University Hospital, Ludwig-Maximilians-University Munich, Germany.

\section{Eligibility criteria}

Patients presenting to primary care with clinical signs and symptoms indicating SIS will be included in the trial. This concept of focusing on important clinical signs for setting up inclusion criteria for a RCT corresponds well with daily clinical practice.

Inclusion criteria: (1) age between 18 and 75 years, (2) symptoms for more than four weeks, (3) main complaints in the glenohumeral joint region or the proximal arm, (4) presence of one of the following signs indicating SIS: Neer impingement test, Hawkins-Kennedy impingement test, painful arc with active abduction or flexion, (5) pain with one of the following resistance tests: external rotation, internal rotation, abduction, or flexion.

Exclusion criteria: (1) average 24-hours pain of $8 / 10$ or more on a visual numeric rating scale (VNRS), (2) primary scapulothoracic dysfunction due to paresis, (3) diagnosed instability or previous history of dislocation, (4) adhesive capsulitis (frozen shoulder), (5) more than 1/ 3 restriction of elevation compared to the unaffected side, (6) substantial shoulder weakness or loss of active shoulder function, (7) shoulder surgery in the last 12 months on the involved side, (8) reproduction of symptoms with active or passive cervical movements, (9) neurological involvement with sensory and muscular deficit, (10) 


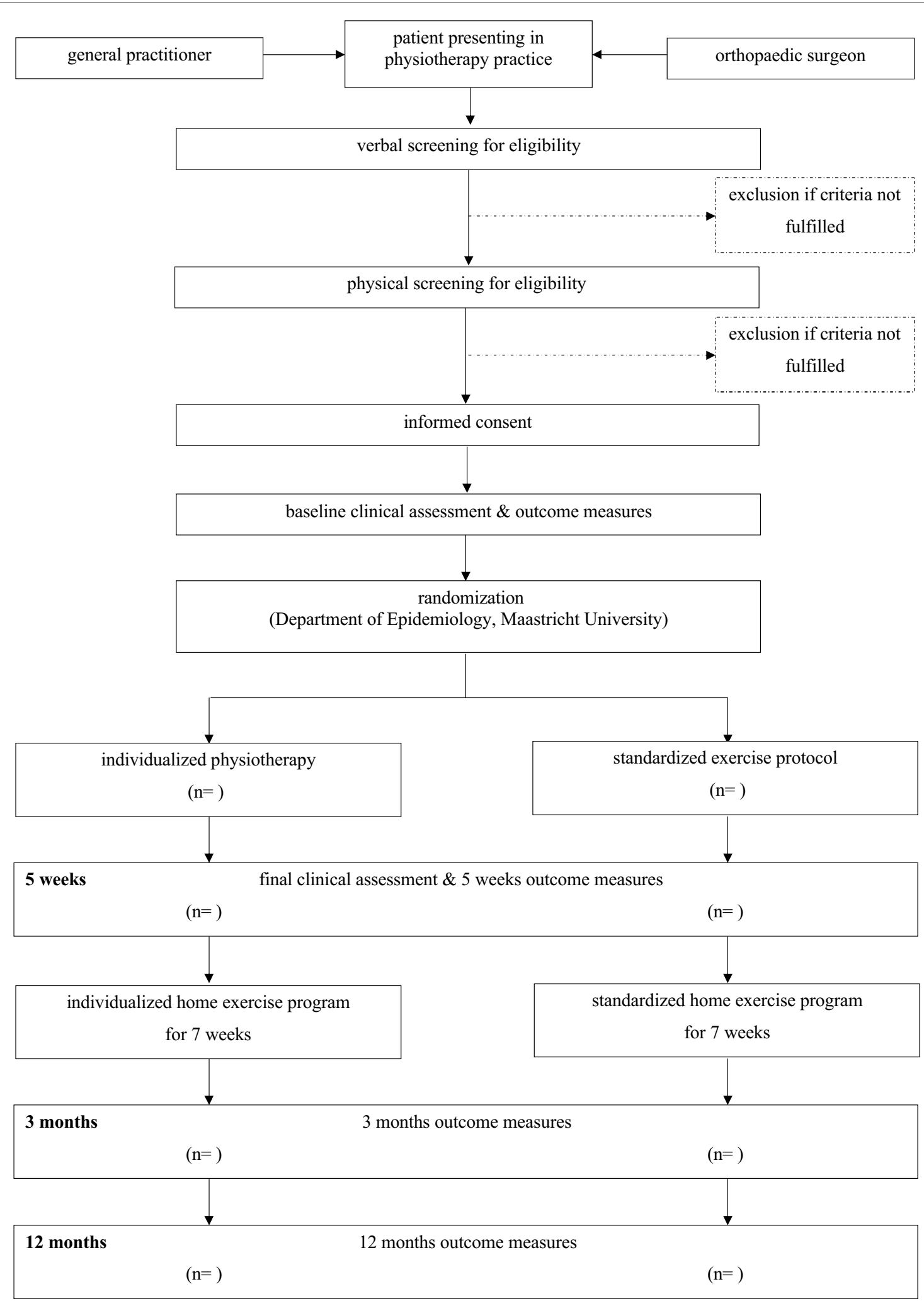


inflammatory joint disease (e.g. rheumatoid arthritis), (11) diabetes mellitus, (12) intake of psychotherapeutic drugs, (13) compensation claims, (14) inability to understand written or spoken German.

\section{Recruitment of participants}

The proposed trial will be embedded in the normal daily process of selected physiotherapy clinics in Germany. Participants will be identified by physiotherapy referrals and by research physiotherapists. If a patient agrees to participate, the research therapist will check eligibility criteria. If eligibility is confirmed, informed consent will be asked. Participants will then undergo baseline assessment including some questionnaires and a standardized clinical examination protocol for the shoulder complex, the cervical and upper thoracic spine.

An inclusion period of eighteen months is thought to be sufficient to recruit the number of participants needed for this study.

\section{Randomization and allocation concealment}

After informed consent and baseline assessment participants will be randomized to either SEP or IP using block allocation of six. To guarantee allocation concealment, therapists will be informed about allocation after the participant completed all baseline measurements and gave informed consent, prior to first treatment by the Department of Epidemiology, Maastricht University.

\section{Interventions}

\section{Both groups}

All participants will undergo a clinical examination process starting with a thorough history taking, followed by a physical examination of the cervical spine, the shoulder girdle, and the shoulder joints. All joints are manually assessed with passive, active, and combined angular movements, and with translatory tests according to the description of Kaltenborn [55], Evjenth and Hamberg [56] or Maitland [57]. Isometric resistance tests are used to judge shoulder strength and pain. Integrity of the rotator cuff is assessed with the external rotation lag sign [58], the lift off test [59], and the hornblowers' sign [60]; involvement of the neural system with upper limb tension tests described by Butler [61]. Contributing factors such as a slouched posture, forward head position, thoracic kyphosis, or protracted shoulders are noted and if necessary also assessed in detail. Results serve as basis for the treatment of participants allocated to the group receiving individualized physiotherapy.

All participants will attend two 20-30 minute contact sessions per week over a 5 week period. Afterwards participants will continue with their home exercises for another 7 weeks. At the beginning of treatment all participants will receive an information booklet containing basic information about anatomy and biomechanics of the shoulder complex, a short description of the aetiology of SIS and the pathology itself, and a brief overview about possible contributing factors to their shoulder pain. The booklet also explains the goals to be achieved with treatment, and it provides general guidelines for behaviour through daily living. Participants will also receive a shoulder log book for documentation of their weekly pain levels, additional treatments or medication, sick leave, and the completion of the home exercise during the intervention phase and during the follow up period. Participants will be requested not to make use of other treatment options and not to change their medication intake during the intervention phase. However, due to ethical considerations the use of analgesics and non-steroidal antiinflammatory drugs will be permitted and will be recorded in the shoulder log-book.

Treatment will be administered by experienced physiotherapists with an international qualification for manual therapy (IFOMPT standard). All physiotherapists will be trained prior to commencement of the study to guarantee a uniform background and treatment application. A written manual with detailed and comprehensive instructions is given to the therapists. Thoroughness of the application is supported by structured recording forms and check lists, monthly team meetings and audits.

The two groups are as follows:

\section{Control group}

Participants assigned to the control group will perform a standard exercise protocol (SEP) aiming at restoring muscular deficits in strength, mobility, or coordination of the rotator cuff and the shoulder girdle, unloading the subacromial space, and centering the humeral head in the glenoid fossa during active movements. Thus, the SEP contains mainly strengthening exercises, stretching and mobility exercises, but also exercises to control pain. To set up a high quality protocol, exercises are taken from papers investigating exercises for shoulder rehabilitation [62-79], and exercises specifically addressing deficits in strength, mobility, or coordination revealed in patients with SIS $[19,23-25,31,80,81]$. Another important criterion for the selection of the exercises was their practicability, their potential for pain provocation, and the possibility to perform all exercises at home with a rubber band. Exercises are subdivided in a "core program" and "additional exercises". A short description of the exercises is provided in Table 1 \&2.

Exercises of the "core program" are introduced and instructed to the patient in detail first, and if patients show good progression, exercises from the pool of "additional exercises" can be added. At home exercises are realized with the help of a PINOFIT rubber band (Pino $\mathrm{GmbH}$, Hamburg, Germany) which allows dynamic resistance and is easy to use. It is available from very light resistance to heavy resistance and allows the therapist to 
Table 1: Exercises of the core program.

\begin{tabular}{|c|c|c|c|}
\hline No. & Exercise & Material & Description \\
\hline $\mathrm{C} 1 \mathrm{a}$ & Low row & $\begin{array}{l}\text { Pinoband or pulley } \\
\text { apparatus with } 2 \\
\text { handles }\end{array}$ & $\begin{array}{l}\text { Subject is sitting in front of pinoband, shoulders in } 80^{\circ} \text { forward flexion } \\
\text { and neutral rotation; subject performs shoulder extension with } \\
\text { elbows flexed. }\end{array}$ \\
\hline $\mathrm{C} 1 \mathrm{~b}$ & High row & $\begin{array}{l}\text { Pinoband or pulley } \\
\text { apparatus with } 2 \\
\text { handles }\end{array}$ & $\begin{array}{l}\text { Subject is sitting in front of pinoband, shoulders in } 100^{\circ} \text { forward } \\
\text { flexion and neutral rotation; subject performs shoulder extension } \\
\text { with elbows extended. }\end{array}$ \\
\hline C2 & $\begin{array}{l}\text { Shoulder adduction in scapular } \\
\text { plane }\end{array}$ & $\begin{array}{l}\text { Pinoband or pulley } \\
\text { apparatus with } 1 \text { handle }\end{array}$ & $\begin{array}{l}\text { Subject is standing, shoulder in } 80^{\circ} \text { abduction in scapular plane; } \\
\text { subject performs shoulder adduction with elbow extended. }\end{array}$ \\
\hline C3a & $\begin{array}{l}\text { Shoulder external rotation in } 0^{\circ} \\
\text { abduction }\end{array}$ & $\begin{array}{l}\text { Pinoband or pulley } \\
\text { apparatus with } 1 \text { handle }\end{array}$ & $\begin{array}{l}\text { Subject is standing, with towel between arm and trunk to prevent } \\
\text { compensatory shoulder movements, elbow flexed to } 90^{\circ} \text {; subject } \\
\text { performs shoulder external rotation. }\end{array}$ \\
\hline $\mathrm{C} 3 \mathrm{~b}$ & $\begin{array}{l}\text { Shoulder external rotation in side- } \\
\text { lying }\end{array}$ & Dumbbell & $\begin{array}{l}\text { Subject is side-lying, with towel between arm and trunk to prevent } \\
\text { compensatory shoulder movements, elbow flexed to } 90^{\circ} \text {; subject } \\
\text { performs shoulder external rotation. }\end{array}$ \\
\hline C4a & $\begin{array}{l}\text { Shoulder internal rotation in } 0^{\circ} \\
\text { abduction }\end{array}$ & $\begin{array}{l}\text { Pinoband or pulley } \\
\text { apparatus with } 1 \text { handle }\end{array}$ & $\begin{array}{l}\text { Subject is standing, with towel between arm and trunk to prevent } \\
\text { compensatory shoulder movements, elbow flexed to } 90^{\circ} \text {; subject } \\
\text { performs shoulder internal rotation. }\end{array}$ \\
\hline C4b & $\begin{array}{l}\text { Shoulder internal rotation in side- } \\
\text { lying }\end{array}$ & Dumbbell & $\begin{array}{l}\text { Subject is side-lying, elbow flexed to } 90^{\circ} \text {; subject performs shoulder } \\
\text { internal rotation. }\end{array}$ \\
\hline C5 & $\begin{array}{l}\text { Elbow flexion with forearm } \\
\text { supination }\end{array}$ & Pinoband or dumbbell & $\begin{array}{l}\text { Subject standing arm at the side, neutral rotation; subject performs } \\
\text { elbow flexion/forearm supination. }\end{array}$ \\
\hline C6a & Horizontal scapular protraction & $\begin{array}{l}\text { Pinoband or pulley } \\
\text { apparatus with } 2 \\
\text { handles }\end{array}$ & $\begin{array}{l}\text { Subject is standing, elbows flexed to } 90^{\circ} \text {; subject performs shoulder } \\
\text { flexion to } 80^{\circ} \text { and elbow extension, then scapular protraction. }\end{array}$ \\
\hline $\mathrm{C} 6 \mathrm{~b}$ & Vertical scapular protraction & Pinoband or dumbbells & $\begin{array}{l}\text { Subject lying supine, elbows flexed to } 90^{\circ} \text {; subject performs shoulder } \\
\text { flexion to } 90^{\circ} \text { and elbow extension, then scapular protraction. }\end{array}$ \\
\hline C7 & $\begin{array}{l}\text { 4-point kneeling scapular } \\
\text { protraction }\end{array}$ & - & $\begin{array}{l}\text { Subject in 4-point kneeling position, hands underneath shoulders } \\
\text { performs dynamic scapular protraction. }\end{array}$ \\
\hline C8 & Scapular setting & - & $\begin{array}{l}\text { Subject lying prone with arms held by the side in external rotation; } \\
\text { subject holds scapulae in depressed and retracted position. }\end{array}$ \\
\hline C9 & Posterior shoulder stretch & - & $\begin{array}{l}\text { Subject is standing, pulling the elbow passively across the body into } \\
\text { horizontal adduction with the opposite arm. }\end{array}$ \\
\hline C10 & Lateral neck stretch & - & $\begin{array}{l}\text { Subject is standing, pulling the head into lateral flexion with the } \\
\text { opposite arm and is adding the shoulder depression to stretch the } \\
\text { ipsilateral neck. }\end{array}$ \\
\hline C11 & Thoracic spine extension & - & $\begin{array}{l}\text { Supine on the floor, hips and knees flexed to } 90 \text { degrees, hands } \\
\text { supporting the neck, with thoracic kyphosis lying on a towel roll. }\end{array}$ \\
\hline
\end{tabular}


progressively adapt resistance to the physical capacity of the patient. Patients are supervised during their contact sessions; their exercise program is monitored, controlled and adapted if necessary. Physiotherapists are allowed to adapt the SEP individually to each patient with respect to the situation of the patient. Therapists who deliver the treatment for the control group remain blinded to the clinical examination results to prevent inadvertent contamination of the SEP.

\section{Intervention group}

Participants assigned to the intervention group will perform the SEP as a home program. Additionally this group will receive six to ten session of individualized physiotherapy (IP), based on the findings of the clinical examination and the individual main complaints of the patient. To guarantee a uniform decision making process and to deliver a defined and repeatable way of treatment application a decision tree was developed. The decision tree was previously tested in patients with SIS to improve weaknesses and to test its practicability. It consists of three parts and directs initial treatment applications. The first part of the decision tree addresses predictive signs for a poor treatment outcome such as recurrent episodes of shoulder pain in the past $[7,9,11,12]$, severe pain or long duration of the current episode [82-84], signs indicating a tear of the rotator cuff $[85,86]$, and restriction of external rotation and/or elevation of the shoulder [9,87].

The second part leads the therapist through factors maintaining or contributing to the patients' problem such as general posture, ADL's, working activities and work place setting, leisure and sports activities, and patients' understanding of his problem. The third part guides through the positive findings of the physical examination of the upper quarter (cervical and upper thoracic spine, shoulder and shoulder girdle). Local factors will be treated according to the manual therapy concepts of Maitland [57], Kaltenborn [88], Evjenth and Hamberg [56], or Butler [61].

For further treatment decisions and as an important part of treatment application a defined clinical reassessment process is implemented, adapted from Jones and Rivett [89]. The reassessment process, based on the testretest-principle, delivers important information about the effect of an applied intervention or technique and thus assists the therapist in further decision making.

\section{Main contrast between both groups}

The main difference between both groups is that the intervention group additionally receives individualized physiotherapy considering all predictive, local or contributing factors that may maintain or contribute to the patients' problem, identified through clinical examination. Therefore this intervention, combining a shoulder specific exercise programme with a defined decision making process and clinical experience, represents a best practice approach.

\section{Outcome measures}

Selection criteria for the outcome measures used in this study were their reliability and validity in relation to the study population, and also their sensitivity to detect change statistically, whether it is relevant to the patient or clinician or not. Another important criterion was their practical applicability in a clinical setting. The main focus is on pain and functioning. Primary outcome measures will be as follows:

\section{Shoulder Pain and Disability Index (SPADI)}

The SPADI is a shoulder specific self-reported questionnaire measuring pain and disability in patients with shoulder pain of musculoskeletal origin [90]. It contains 5 items assessing pain and 8 items assessing shoulder function and is easily applicable in daily practice. Each item is scored on a $100 \mathrm{~mm}$ visual analogue scale (VAS); the right end of the VAS is defined as "worst pain imaginable/ so difficult required help", the left end as "no pain/no difficulty". A score is then calculated out of 100 with higher scores reflecting higher pain/disability levels. The SPADI has shown to be valid and highly responsive in assessing shoulder pain and function [90,91]; it is therefore highly recommended for the use in patients with SIS [92]. The German version of the SPADI also showed an excellent reliability and internal consistency for both, total score and sub-scores. A minimum improvement in the total SPADI score of 11 points will be considered as a minimum clinically important change [93].

\section{Patients' global impression of change (PGIC)}

Measuring PGIC is a clinically relevant and stable concept for interpreting truly meaningful improvements in pain from the individual perspective $[94,95]$. It is measured with the help of an ordinal scale with 1-much worsened, 2-slightly worsened, 3-unchanged, 4-slightly better, 5-much better, whereas a rating of "slightly better" will be defined a priori as a clinically important and meaningful difference and therefore as a successful result. According to this definition, the scale is then dichotomized. To test stability of this dichotomization a sensitivity analysis will be conducted.

Secondary outcome measures will be:

\section{Generic Patient-Specific Scale (GPSS)}

The GPSS is published by Stratford et al. [96] and assesses individual complaints and restrictions in a short and efficient way. It is based on the patient-centred approach, identifying the most problematic areas of functioning.

The GPSS is a reliable and valid tool and also sensitive to detect change over time [97]. Although it is a generic outcome measure, its validity, reliability and sensitivity has been established for different patient groups $[96,98,99]$. For this study, patients will chose 3 activities 
Table 2: Additional exercises.

\begin{tabular}{|c|c|c|c|}
\hline No. & Exercise & Material & Description \\
\hline A1a & $\begin{array}{l}\text { Shoulder abduction in } \\
\text { scapular plane (scaption) }\end{array}$ & Pinoband or dumbbell & $\begin{array}{l}\text { Subject is standing with feet on the pinoband; subject performs } \\
80^{\circ} \text { of scaption with elbows slightly flexed and external rotation } \\
\text { of the shoulder (thumb up). }\end{array}$ \\
\hline$A 1 b$ & Shoulder flexion & Pinoband or dumbbell & $\begin{array}{l}\text { Subject is standing with feet on the pinoband; subject performs } \\
80^{\circ} \text { of shoulder flexion with elbows slightly flexed and external } \\
\text { rotation of the shoulder (thumb up). }\end{array}$ \\
\hline A2a & Shoulder press via flexion & Pinoband or dumbbell & $\begin{array}{l}\text { Subject is sitting with back supported. Upper arms are in } \\
\text { contact with the trunk, elbows are maximally flexed and hands } \\
\text { in front of shoulders; subject performs full shoulder flexion and } \\
\text { elbow extension. }\end{array}$ \\
\hline $\mathrm{A} 2 \mathrm{~b}$ & Shoulder press via abduction & Pinoband & $\begin{array}{l}\text { Subject is sitting with back supported. Upper arms are in } \\
\text { contact with the trunk, elbows are maximally flexed and hands } \\
\text { next to shoulders; subject performs full shoulder abduction and } \\
\text { elbow extension. }\end{array}$ \\
\hline A3 & Horizontal abduction & $\begin{array}{l}\text { Pinoband or pulley } \\
\text { apparatus with } 1 \\
\text { handle }\end{array}$ & $\begin{array}{l}\text { Subject is sitting in front of pinoband attached in shoulder } \\
\text { height, shoulders in } 80^{\circ} \text { forward flexion and external rotation; } \\
\text { subject performs horizontal shoulder abduction with nearly } \\
\text { extended elbows. }\end{array}$ \\
\hline A4 & $\begin{array}{l}\text { External rotation in supported } \\
80^{\circ} \text { shoulder flexion }\end{array}$ & $\begin{array}{l}\text { Pinoband or pulley } \\
\text { apparatus with } 1 \\
\text { handle }\end{array}$ & $\begin{array}{l}\text { Subject is sitting with elbow supported on a table in } 80^{\circ} \text { of } \\
\text { shoulder flexion and } 90^{\circ} \text { elbow flexion. Pinoband fixed on the } \\
\text { table with other hand; subject performs } 90^{\circ} \text { of external rotation. }\end{array}$ \\
\hline A5 & $\begin{array}{l}\text { Internal rotation in supported } \\
80^{\circ} \text { shoulder flexion }\end{array}$ & $\begin{array}{l}\text { Pinoband or pulley } \\
\text { apparatus with } 1 \\
\text { handle }\end{array}$ & $\begin{array}{l}\text { Subject is sitting with elbow supported with the other hand in } \\
80^{\circ} \text { of shoulder flexion, pinoband fixed in waste height; subject } \\
\text { performs } 90^{\circ} \text { of internal rotation. }\end{array}$ \\
\hline A6a & $\begin{array}{l}\text { Shoulder protraction in } \\
\text { kneeling push up position }\end{array}$ & - & $\begin{array}{l}\text { Subject in kneeling push up position, hands underneath } \\
\text { shoulders and knees behind hips; subject performs dynamic } \\
\text { scapular protraction. }\end{array}$ \\
\hline A6b & $\begin{array}{l}\text { Shoulder protraction in push } \\
\text { up position }\end{array}$ & - & $\begin{array}{l}\text { Subject in push up position; subject performs dynamic scapular } \\
\text { protraction. }\end{array}$ \\
\hline A6c & Half way push up plus & - & $\begin{array}{l}\text { Subject in push up position; subject performs a half way push } \\
\text { up with a dynamic scapular protraction at the end of arm } \\
\text { extension. }\end{array}$ \\
\hline AM1 & Internal rotation positioning & - & $\begin{array}{l}\text { Subject is placing the hand on the buttock or lower back in a } \\
\text { pain-free manner, supported by the other hand. }\end{array}$ \\
\hline AP1 & Pendulum exercises & Dumbbell or bottle & $\begin{array}{l}\text { Subject is standing leaning on a chair or table with the good } \\
\text { arm and bending forward at the waist. Relax the shoulder blade } \\
\text { and let it drop. Subject performs relaxed forward-backward } \\
\text { swings and circle swings using body motion. }\end{array}$ \\
\hline AP2 & $\begin{array}{l}\text { Longitudinal shoulder } \\
\text { traction }\end{array}$ & Pinoband & $\begin{array}{l}\text { Subject is standing and slightly side bent with pinoband is } \\
\text { wrapped around the wrist and fixed with the feet on the } \\
\text { bottom with tension. Subject is relaxing the shoulder to allow } \\
\text { for longitudinal traction. }\end{array}$ \\
\hline
\end{tabular}


they got difficulties with and rate the ability to perform them on an 11-point visual numeric rating scale (VNRS). 10 at the right end of the VNRS is defined as "I can do the chosen function without difficulty", 0 at the left end as "I am unable to do the chosen function". An average score across all activities is calculated. Because the expected change of severely restricted activities is less than the expected change of only mild restrictions, a minimum change of $30 \%$ will be considered as a clinically important improvement $[95,100]$.

\section{Average weekly pain score}

Patients will rate their average weekly pain intensity on an 11-point VNRS. The VNRS is a one-dimensional measure to assess pain intensity. The distance between each number is 10 millimetres; 0 on the left end of the VNRS is defined as "no pain at all", 10 at the right end as "as much pain as I can imagine". An improvement in pain level of 2 points or more was defined as a clinically important and meaningful difference $[95,100]$.

\section{Patient satisfaction with treatment}

After 5 weeks all patients will rate their satisfaction with treatment on an 11-point visual numeric rating scale (VNRS). 10 at the right end of the VNRS is defined as "completely satisfied", 0 at the left end as "completely dissatisfied".

\section{Fear Avoidance Beliefs Questionnaire (FABQ)}

It has been shown that fear of movement is an important obstacle to a successful rehabilitation in patients suffering from low back pain. To be able to analyze the influence of fear of movement on treatment outcome in patients with SIS, a modified version of the FABQ is used in this study. The FABQ was developed by Waddell et al. [101] to assess the influence of patients beliefs about physical activity and work on low back pain. The German version of the FABQ shows good psychometric properties and is therefore used in this study [102-105]. The FABQ is a 16items questionnaire. Each item is scored on a seven-point Likert scale $(0=$ strongly disagree, $6=$ strongly agree $)$. A total score is calculated by summing up the resultant scores. Sub-scores for physical activity and work are calculated, with 7 items assessing beliefs about work (item 6 , $7,9,10,11,12,15)$ and 4 items assessing beliefs about physical activity (item 2, 3, 4, 5). Higher scores reflect a higher presence of fear avoidance believes.

\section{Pain Catastrophizing Scale (PCS)}

Besides fear of movement, catastrophizing may also play an important role in mediating responses to pain, leading to perception of higher pain intensities and therefore influencing treatment outcome negatively [106-108]. The PCS is a multidimensional, reliable and valid 13-item self report measurement tool with a strong association to pain and emotional distress $[106,107,109,110]$. The PCS has been validated for the German population [111]. It comprises three subscales for rumination (item 8 to 11), magnification (item 6 to 7, 13), and helplessness (item 1 to 5,12 ). Each item is rated on a 5-point scale from 0 (not at all) to 4 (all the time). A total score and sub-scores for each subscale are calculated by summing up the ratings for each item within a subscale. In a sample of 86 patients with sustained soft tissue injuries to the neck, shoulders or back including shoulder patients, Sullivan et al. [112] found that catastrophizing was significantly correlated with patients' reported pain intensity, disability and employment status. The rumination subscale was the strongest predictor of pain and disability. Due to a sufficient test-retest stability even over a longer period of time the PCS is a appropriate screening tool for pain catastrophizing [113].

\section{Patients' expectancies of treatment outcome}

Patients' beliefs about the success of a given treatment may influence treatment outcome; this has been shown by Goossens et al. [114] and Smeets et al. [115] in low back pain patients. For this trial a modified question of the Credibility/Expectancy Questionnaire (CEQ), developed by Deviliya and Borkovecb [116], to measure patients' expectancies is used. The CEQ shows high internal consistency and good test-retest reliability. The question is: "By the end of the therapy period, how much improvement in your limitations due to shoulder pain do you think will occur? The question is scored on an 11point visual numeric rating scale (VNRS) from 0 (no improvement) to 10 (completely recovered). A higher score will reflect more positive expectancies.

\section{Compliance with treatment, direct (health care) and indirect (non-health care) costs}

A shoulder log book will be used to obtain the following data: i) Compliance of participants with treatment including the attended treatment visits out of a maximum of ten and the performance of the given home exercises; ii) direct health care costs including physiotherapy, other health provider visits, diagnostic tests, prescriptions and over the counter medication due to shoulder complaints; iii) indirect health care costs including days of sick leave and paid help. The log book is presented in booklet form containing instructions and explanations about the objective of the log book. Log-books will be posted back to the assessor and checked for completion every two months.

Demographic information will also be collected including age, sex, height, weight, profession, sports and leisure activities, medical history, and medication intake. Information about severity and duration of symptoms and previous episodes of shoulder pain are also documented.

\section{Follow-up evaluation}

Patients are assessed at baseline, after completion of the intervention period at 5 weeks, and at 3 and 12 months after inclusion to assess the long term outcome of the 
Table 3: Primary and secondary outcome measures

\begin{tabular}{|c|c|c|}
\hline Primary Outcomes & Measurement & Follow up \\
\hline Shoulder pain and disability index (SPADI) & $\begin{array}{l}13 \text { items ( } 5 \text { for pain, } 8 \text { for function) scored } \\
\text { on a } 100 \mathrm{~mm} \text { visual analogue scale }\end{array}$ & baseline; 5 weeks; 3,12 months \\
\hline Patients' global impression of change & $\begin{array}{l}\text { Ordinal scale ( } 1 \text {-much worse, } 2 \text {-slightly } \\
\text { worse, 3-no change, } 4 \text {-slightly better, } 5 \text { - } \\
\text { much better) }\end{array}$ & 5 weeks; 3,12 months \\
\hline Secondary Outcomes & Measurement & Follow up \\
\hline Generic patient-specific scale & $\begin{array}{l}11 \text { point visual numeric rating scale (end } \\
\text { descriptors of } 0=\text { impossible to do, } 10=\text { no } \\
\text { difficulties at all) }\end{array}$ & baseline; 5 weeks; 3,12 months \\
\hline Average weekly pain score & $\begin{array}{l}11 \text { point visual numeric rating scale (end } \\
\text { descriptors of } 0=\text { no pain, } 10=\text { worst pain } \\
\text { possible) }\end{array}$ & baseline; 5 weeks; 3 months \\
\hline Patients' satisfaction with treatment & $\begin{array}{l}11 \text { point visual numeric rating scale (end } \\
\text { descriptors of } 0=\text { completely dissatisfied, } \\
10=\text { completely satisfied) }\end{array}$ & 5 weeks \\
\hline Kinesiophobia/Fear avoidance beliefs & $\begin{array}{l}\text { Modified fear avoidance beliefs } \\
\text { questionnaire (FABQ) }\end{array}$ & Baseline \\
\hline Catastrophizing & Pain catastrophizing scale (PCS) & Baseline \\
\hline Patients' expectancies of treatment effect & $\begin{array}{l}\text { One modified question from the } \\
\text { Credibility/Expectancy Questionnaire } \\
\text { (CEQ) }\end{array}$ & Baseline \\
\hline Compliance & $\begin{array}{l}\text { Shoulder log book: Attention of treatment } \\
\text { sessions and completion and frequency of } \\
\text { home exercises }\end{array}$ & 5 weeks; 3,12 months \\
\hline Costs & $\begin{array}{l}\text { Cost diary: Disease specific healthcare } \\
\text { utilization, days of sick leave, drug use, } \\
\text { paid help }\end{array}$ & 5 weeks; 3,12 months \\
\hline
\end{tabular}

intervention. An overview of the outcome measures is given in Table 3.

\section{Sample size}

Sample size for this trial is based on an expected difference between groups of a 13 points reduction of the SPADI score. The statistical level of significance was set to alpha $=0.05$, statistical power to $80 \%$, and a $15 \%$ drop out rate was expected. The assumed standard deviation was set to 20 points based on the results of other studies [117-120]. Power calculations resulted in an estimated sample size of 90 participants (45 per group) to detect a 13 points difference in SPADI score. The minimum clini- cally important change is set to an 11 points improvement in total SPADI score [93].

\section{Data analysis}

First, descriptive statistics for demographical characteristics of the whole group will be used. Second, descriptive statistics for demographical and clinical characteristics, for baseline results of outcome measures and other potential confounding variables for the intervention group and control group will be used. Differences will be calculated for within-groups results and between-groups comparisons. Results will be calculated according to the "intention-to-treat principle". Between groups-analysis 
will include differences between baseline and follow up measurements for each clinical outcome measure used, their standard deviations and 95\% confidence intervals. Additionally mixed models for the long term follow ups will be used. Influence of baseline differences for outcome measures will be assessed in a multivariable linear regression analysis. Statistical significance is set to $\mathrm{p} \leq$ 0.05 , clinical importance will be judged by the lower $95 \%$ confidence interval which equals the minimum effect size.

An economic evaluation will compare costs of both treatment options from a societal perspective.

Resources recorded in the shoulder log book will be valued using published prices for medical costs. Costs for over the counter drugs, aids, and paid help will be reported directly by the participants in their log-books.

Productivity costs resulting from loss of paid labor will also be calculated by applying the friction costs method, which limits the period of production loss to the time during the work of the person is not replaced.

Between-group differences in outcomes of mean total costs were analyzed by Student's $t$-tests for unpaired observations.

\section{Results}

Inclusion of participants has started in April 2010. First results are expected in 2012, long term results in 2013.

\section{Discussion}

In order to compare the effectiveness of individualized physiotherapy to a standard exercise protocol a randomized controlled trial design will be used. Our diagnostic and eligibility criteria are purely based on clinical signs and symptoms which correspond very well with clinical practice, and the population usually seen in primary care is well reflected.

Exercises, as a quite simple form of physiotherapeutic treatment, has been shown to be as effective as other physiotherapy-led interventions in the treatment of SIS and are therefore often recommended. However, most investigated forms of physiotherapy-led interventions have been applied as standard protocols without considering individual needs and may be therefore limited in their effect. In this study, treatment of the intervention group, guided by a defined decision making process will address the individual activity and participation restrictions of each patient, predictive signs for a poor outcome, contributing and local factors. To reveal the additional benefit of this intervention, participants of the intervention group will also perform the SEP as a home program.

To strengthen the validity of the trial results, important qualitative methodological factors have been considered in the planning stage of this trial. To prevent selection bias, participants will be randomly allocated to groups via concealed allocation sequence, implemented by a remote clinical trial centre. To minimize performance bias, physiotherapists treating the active control group remain blinded to the results of the clinical examination to prevent contamination of the SEP. Further the statistician remains blinded to group assignment of the participants. Outcome measures used in this trial are easy to apply in daily practice.

To our knowledge this is the first trial comparing individualized physiotherapy led by a defined decision making process to a standard exercise protocol. Results from this trial will add evidence to the limited body of knowledge about the effect of physiotherapy in patients with SIS.

Competing interests

The authors declare that they have no competing interests.

\section{Authors' contributions}

TOK conceived of the project, led the design and co-ordination of the trial, and wrote the first draft of the manuscript. RADB and CHGB participated in the study design and commented on drafts of this paper. CHGB provided advice for the method section. All authors have reviewed and approved the final manuscript.

\section{Acknowledgements}

We are grateful to Prof. Dr. Ernst Wiedemann from the OCM Munich (Germany) for his help with submitting the study protocol to the Ethical Committee of the LMU Munich.

We also give thanks to the Pino GmbH Hamburg (Germany) for providing the Pinofit-elastic band.

\section{Author Details}

1Physiotherapiezentrum, Grube 21, 82377 Penzberg, Germany, 2Department of Epidemiology, Maastricht University, P.O. Box 616, 6200 MD Maastricht, the Netherlands, ${ }^{3}$ CAPHRI School for Public Health and Primary Care, Maastricht University, P.O. Box 616, 6200 MD Maastricht, the Netherlands and ${ }^{4}$ Centre for Evidence-Based Physiotherapy (CEBP), Maastricht University, P.O. Box 616, 6200 MD Maastricht, the Netherlands

Received: 17 March 2010 Accepted: 9 June 2010

Published: 9 June 2010

\section{References}

1. Huisstede BMA, Bierma-Zeinstra SMA, Koes BW, Verhaar JAN: Incidence and prevalence of upper-extremity musculoskeletal disorders. a systematic appraisal of the literature. BMC Musculoskeletal Disorders 2006, 7:

2. Rekola KE, Keinanen-Kiukaanniemi S, Takala J: Use of primary health services in sparsely populated country districts by patients with musculoskeletal symptoms: consultations with a physician. Journal of Epidemiology and Community Health 1993, 47:

3. Luime JJ: Shoulder complaints: the occurrence, course and diagnosis. In Proefschrift Erasmus Universiteit; 2004.

4. van der Heijden GJ: Shoulder disorders: a state of the art review. Baillieres Clinical Rheumatology 1999, 13:287-309.

5. van der Windt DA, Koes BW, de Jong BA, Bouter LM: Shoulder disorders in general practice: incidence, patient characteristics, and management. Annals of Rheumatic Diseases 1995, 54:959-964.

6. Östör AJK, Richards CA, Prevost AT, Speed CA, Hazleman BL: Diagnosis and relation to general health of shoulder disorders presenting to primary care. Rheumatology 2005, 44:800-805.

7. Luime JJ, Hendriksen IJM, Burdorf A, Verhagen AP, Miedema HS, Verhaar JAN: Prevalence and incidence of shoulder pain in the general population; a systematic review. Scandinavian Journal of Rheumatology 2004, 33:73-81. 
8. Gartsman GM, Brinker MR, Khan M, Karahan M: Self-assessment of general health status in patients with five common shoulder complaints. Journal of Shoulder and Elbow Surgery 1998, 7:228-237.

9. Croft PR, Pope DP, Silman AJ: The clinical course of shoulder pain: prospective cohort study in primary care. British Medical Journal 1996, 313:601-602.

10. Linsell L, Dawson J, Zondervan K, Rose P, Randall T, Fitzpatrick R, Carr A: Prevalence and incidence of adults consulting for shoulder conditions in UK primary care; patterns of diagnosis and referral. Rheumatology 2006, 45:215-221.

11. Winters JC, Sobel JS, Groenier KH, Arendzen JH, Meyboom-de Jong B: The long-term course of shoulder complaints: a prospective study in general practice. Rheumatology 1999, 38:160-163.

12. Bot SDM, van der Waal JM, Terwee CB, van de Windt DAWM, Scholten RJPM, Bouter LM, Dekker J: Predictors of outcome in neck and shoulder symptoms. Spine 2005, 30:E459-E470.

13. Lewis JS, Green AS, Dekel S: The aetiology of subacromial impingement syndrome. Physiotherapy 2001, 87:458-469.

14. Deutsch A, Altchek DW, Schwartz E, Otis JC, Warren RF: Radiologic measurement of superior displacement of the humeral head in the impingement syndrome. Journal of Shoulder and Elbow Surgery 1996, 5:186-193.

15. Ebaugh DD, McClure PW, Karduna AR: Scapulotharacic and glenohumeral kinematics following an external rotation fatigue protocol. Journal of Orthopaedic and Sports Physical Therapy 2006, 36:557-571.

16. Meister K, Andrews JR: Classification and treatment of rotator cuff injuries in the overhead athlete. Journal of Orthopaedic and Sports Physical Therapy 1993, 18:413-420.

17. Sharkey NA, Marder RA: The rotator cuff opposes superior translation of the humeral head. The American Journal of Sports Medicine 1995, 23:270-275

18. Leroux J-L, Codine P, Thomas E, Pocholle M, Mailhe D, Blotman F: Isokinetic evaluation of rotational strength in normal shoulders and shoulders with impingement syndrome. Clinical Orthopaedics and Related Research 1994, 304:108-113.

19. Reddy AS, Mohr KJ, Pink MM, Jobe FW: Electromyographic analysis of the deltoid and rotator cuff muscles in persons with subacromial impingement syndrome. Journal of Shoulder and Elbow Surgery 2000, 9:519-523.

20. Warner JJP, Micheli $\sqcup$, Arslanian LE, Kennedy J, Kennedy R: Pattern of flexibility, laxity, and strength in normal shoulders and shoulders with instability and impingement. American Journal of Sports Medicine 1990, 18:366-375.

21. Irlenbusch U, Gansen H-K: Muscle biopsy investigations on neuromuscular insufficiency of the rotator cuff: a contribution to the functional impingement syndrome of the shoulder. Journal of Shoulder and Elbow Surgery 2003, 12:422-426.

22. Wadsworth DJS, Bullock-Saxton JE: Recruitment patterns of scapular rotator muscles in freestyle swimmers with subacromial impingement. Int Journal Sports Med 1997, 18:618-624.

23. Ludewig PM, Cook TM: Alterations in shoulder kinematics and associated muscle activity in people with symptoms of shoulder impingement. Physical Therapy 2000, 80:276-291.

24. Cools AM, Witvrouw EE, Declercq GA, Danneels LA, Cambier DC: Scapular muscle recruitment patterns: Trapezius muscle latency with and without impingement symptoms. The American Journal of Sports Medicine 2003, 31:542-549.

25. Cools AM, Witvrouw EE, Mahieu NN, Danneels LA: Isokinetic scapular muscle performance in overhead athletes with and without impingement syndrome. Journal of Athletic Training 2005, 40:104-110.

26. Kibler BW: The Role of the Scapula in Athletic Shoulder Function. American Journal of Sports Medicine 1998, 26:325-337.

27. Neer CS: Impingement syndrome in the shoulder. Journal of Bone and Joint Surgery 1972, 54-A:41-50

28. Neer CS: Impingement lesions. Clinical Orthopaedics and Related Research 1983, 173:70-77.

29. Bigliani LU, Morrison DS, April EW: Morphology of the acromion and its relationship to rotator cuff tears. Orthopaedic Trans 1986, 10:459-460.

30. Glousman R, Jobe FW, Tibone J, Moynes D, Antonelli D, Perry J: Dynamic electromyographic analysis of the throwing shoulder with glenohumeral instability. Journal of Bone and Joint Surgery 1988, 70A:220-226.

31. Tyler TF, Nicholas SJ, Roy T, Gleim GW: Quantification of posterior capsule tightness and motion loss in patients with shoulder impingement. American Journal of Sports Medicine 2000, 28:668-673.

32. Matsen FA, Arntz CT, Lippitt SB: Rotator cuff. In The Shoulder Volume 1 2nd edition. Edited by: Rockwood CA, Matsen FA. Philadelphia: W.B. Saunders; 1998:755-795.

33. Harryman DT, Slides JA, Clark JM, McQuade KJ, Gibb TD, Matsen FA III: Translation of the humeral head on the glenoid with passive glenohumeral motion. Journal of Bone and Joint Surgery 1990, 72A:1334-1343.

34. Bullock MP, Foster NE, Wright CC: Shoulder impingement: the effect of sitting posture on shoulder pain and range of motion. Manual Therapy 2005:28-37.

35. Solem-Bertoft E, Thuomas K-A, Westerberg C-E: The Influence of scapular retraction and protraction on the width of the subacromial space. Clinical Orthopaedics and Related Research 1993, 296:99-103.

36. Vlaeyen JWS, Linton SJ: Fear-avoidance and its consequences in chronic musculoskeletal pain:a state of the art. Pain 2000, 85:317-332.

37. Feleus A, van Dalen T, Bierma-Zeinstra SMA, Bernsen RMD, Verhaar JAN, Koes BW, Miedema HS: Kinesiophobia in patients with non-traumatic arm, neck and shoulder complaints: a prospective cohort study in general practice. BMC Musculosceletal Disorders 2007, 8:117.

38. Karels $\mathrm{CH}$, Bierma-Zeinstra SMA, Burdorf A, Verhagen AP, Nauta AP, Koes BW: Social and psychological factors influenced the course of arm, neck and shoulder complaints. Journal of Clinical Epidemiology 2007, 60:839-848

39. Lundberg M, Larsson M, Östlund H, Styf J: Kinesiophobia among patients with musculoskeletal pain in primary healthcare. Journal of Rehabilitation Medicine 2006, 38:37-43.

40. van der Windt DAM, Kuijpers T, Jellema P, van der Heijden GJMG, Bouter LM: Do psychological factors predict outcome in both low-back pain and shoulder pain? Annals of the Rheumatic Diseases 2007, 66:313-319.

41. De Bruijn C, de Bie R, Gereats J, Goossens M, van der Heuvel W, van der Heijden GJ, Candel M, Dinant G-J: Effect of an education and activation programme on functional limitations and patient-perceived recovery in acute and sub-acute shoulder complaints -- a randomised clinical trial. BMC Musculoskeletal Disorders 2007, 8:

42. Dinnes J, Lovemann E, McIntyre L, Waugh N: The effectiveness of diagnostic tests of the assessment of shoulder pain due to soft tissue disorders: a systematic review. Health Technology Assessment 2003, 7:1-175

43. Read JW, Perko M: Shoulder ultrasound: Diagnostic accuracy for impingement syndrome, rotator cuff tear, and biceps tendon pathology. Journal of Shoulder and Elbow Surgery 1998, 7:264-271.

44. Sher JS, lannotti JP, Williams GR, Herzog RJ, Kneeland JB, Llisser S, Patel N: The effect of shoulder magnetic resonance imaging on clinical decision making. Journal of Shoulder and Elbow Surgery 1998, 7:205-209.

45. Awerbuch MS: The clinical utility of ultrasonography for rotator cuff disease, shoulder impingement syndrome and subacromial bursitis. Medical Journal of Australia 2008, 188:50-53.

46. Ardic F, Kahraman Y, Kacar M, Kahraman MC, Findikoglu G, Yorgancioglu ZR: Shoulder impingement syndrome: relationships between clinical, functional, and radiologic findings. American Journal of Physical Medicine \& Rehabilitation 2006, 85:53-60.

47. Teefey SA, Rubin DA, Middleton WD, Hildebolt CF, Leibold RA, Yamaguchi $\mathrm{K}$ : Detection and quantification of rotator cuff tears. comparison of ultrasonographic, magnetic resonance imaging, and arthroscopic findings in seventy-one consecutive cases. Journal of Bone and Joint Surgery 2004, 86:708-716.

48. Peters $D$, Davies $P$, Pietroni $P$ : Musculoskeletal clinic in general practice: study of one year's referrals. British Journal of Gneral Practice 1994, 44:25-29.

49. Faber E, Kuiper J, Burdorf A, Miedema HS, Verhaar JAN: Treatment of impingement syndrome: a systematic review of the effects on functional limitations and return to work. Journal of Occupational Rehabilitation 2006, 16:7-25.

50. Green SE, Buchbinder R, Hetrick S: Physiotherapy interventions for shoulder pain. The Cochrane Database of Systematic Reviews, Issue 2 Art No: CD004258 2003a. 
51. Michener LA, Walsworth MK, Burnet EN: Effectiveness of rehabilitation for patients with subacromial impingement syndrome: a systematic review. Journal of Hand Therapy 2004, 17:152-164.

52. Kuhn JE: Exercise in the treatment of rotator cuff impingement: $A$ systematic review and a synthesized evidence-based rehabilitation protocol. Journal of Shoulder and Elbow Surgery 2009, 18:138-160.

53. WHO: ICF - Internationale Klassifikation der Funktionsfähigkeit, Behinderung und Gesundheit. Köln: Deutsches Institut für Medizinische Dokumentation und Information (DIMDI); 2005.

54. Jones M, Edwards I, Grimmer K, Higgs J, Tede F: Challenges of applying best evidence to physiotherapy: Part 2 - health and clinical reasoning models to facilitate evidence-based practice. Internet Journal of Allied Health Sciences and Practice 2006, 4:1-8.

55. Kaltenborn F: Wirbelsäule - Manuelle Untersuchung und Mobilisation. Oslo: Olaf Noris Bokhandel; 1992.

56. Evjenth $\mathrm{O}$, Hamberg J: Muscle stretching in manual therapy. Alfta: Alfta Rehab; 1998.

57. Maitland GD: Manipulation der Wirbelsäule. 2nd edition. Berlin: Springer Verlag; 1994.

58. Hertel R, Ballmer FT, Lombert SM, Gerber C: Lag signs in the diagnosis of rotator cuff rupture. Journal of Shoulder and Elbow Surgery 1996, 5:307-313.

59. Gerber C, Krushell RJ: Isolated rupture of the tendon of the subscapularis muscle. Clinical features in 16 cases. Journal of Bone and Joint Surgery 1991, 73B:389-394.

60. Walch G, Boulahia A, Calderone S, Robinson AHN: The 'dropping' and 'hornblower's' signs in evaluation of rotator-cuff tears. Journal of Bone and Joint Surgery Br 1998, 80:624-628.

61. Butler DS: Mobilisation des Nervensystems. Berlin: Springer Verlag; 1995

62. Hintermeister RA, Lange GW, Schultheis JM, Bey MJ, Hawkins RJ: Electromyographic activity and applied load during shoulder rehabilitation exercises using elastic resistance. The American Journal of Sports Medicine 1998, 26:210-220.

63. Decker MJ, Hintermeister RA, Faber KJ, Hawkins RJ: Serratus anterior muscle activity during selected rehabilitation exercises. The American Journal of Sports Medicine 1999, 27:784-791.

64. Alpert SW, Pink MM, Jobe FW, McMahon PJ, Mathiyakom W: Electromyographic analysis of deltoid and rotator cuff function under varying loads and speeds. Journal of Shoulder and Elbow Surgery 2000, 9:47-58.

65. Jenp Y-N, Malanga GA, Growney ES, An K-N: Activation of the rotator cuff in generating isometric shoulder rotation torque. The American Journal of Sports Medicine 1996, 24:477-485.

66. Kelly BT, Kadrmas WR, Speer KP: The manual muscle examination for rotator cuff strength. The American Journal of Sports Medicine 1996, 24:581-587.

67. Kronberg M, Broström L-A: Electromyographic recordings in shoulder muscles during eccentric movements. Clinical Orthopaedics and Related Research 1995, 314:143-151.

68. Lear LJ, Gross MT: An electromyographical analysis of the scapular stabilizing synergists during a push up progression. Journal of Orthopaedic and Sports Physical Therapy 1998, 28:146-157.

69. Levy AS, Kelly BT, Lintner SA, Osbahr DC, Speer KP: Function of the long head of the biceps at the shoulder: Electromyographic analysis. Journal of Shoulder and Elbow Surgery 2001, 10:250-255

70. Swanik KA, Lephart SM, Swanik B, Lephart SP, Stone DA, Fu FH: The effects of shoulder plyometric training on proprioception and selected muscle performance characteristics. Journal of Shoulder and Elbow Surgery 2002, 11:579-586.

71. Reinold MM, Wilk KE, Fleisig GS, Zheng N, Barrentine SW, Chmielewski T, Cody RC, Jamerson GG, Andrews JR: Electromyographic analyses of the rotator cuff and deltoid musculature during common shoulder external rotation exercises. Journal of Orthopaedic and Sports Physical Therapy 2004, 34:385-394

72. Uhl TL, Carver TJ, Mattacola CG, Mair SD, Nitz JA: Shoulder musculature activation during upper extremity weight bearing exercise. Journal of Orthopaedic and Sports Physical Therapy 2003, 33:109-117.

73. Moseley BJ, Jobe FW, Pink MM, Perry J, Tibone J: EMG analysis of the scapular muscles during a shoulder rehabilitation program. American Journal of Sports Medicine 1992, 20:128-134.
74. Lintner D, Mayol M, Uzodinma O, Jones R, Labossiere D: Glenohumeral Internal Rotation Deficits in Professional Pitchers Enrolled in an Internal Rotation Stretching Program. American Journal of Sports Medicine 2007, 35:617-621.

75. Reinold MM, Escamilla R, Wilk KE: Current concepts in the scientific and clinical rationale behind exercises for glenohumeral and scapulothoracic musculature. Journal of Orthopaedic \& Sports Physical Therapy 2009, 39:106-117.

76. Reinold MM, Macrina LC, Wilk KE, Fleisig GS, Dun S, Barrentine SW, Ellerbusch MT, Andrews JR: Electromyographic analysis of the supraspinatus and deltoid muscles during 3 common rehabilitation exercises. Journal of Athletic Training 2007, 42:464-469.

77. Townsend $\mathrm{H}$, Jobe FW, Pink M, Perry J: Electromyographic analysis of the glenohumeral muscles during a baseball rehabilitation programme. The American Journal of Sports Medicine 1991, 19:264-272.

78. McClure P, Balaicuis J, Heiland D, Broersmsma ME, Thorndike CK, Wood A: A randomized controlled comparison of stretching procedures for posterior shoulder tightness. Journal of Orthopaedic and Sports Physical Therapy 2007, 37:108-113.

79. Cools AM, Dewitte V, Lanszweert F, Notebaert D, Roets A, Soetens B, Cagnie B, Witvrouw EE: Rehabilitation of scapular muscle balance: which exercises to prescribe? American Journal of Sports Medicine 2007, 35:1744-1750

80. Leroux J-L, Codine P, Thomas E, Pocholle M, Mailhe D, Blotman F: Isokinetic evaluation of rotational strength in normal shoulders and shoulders with impingement syndrome. Clinical Orthopaedics and Related Research 1994, 304:108-115.

81. Warner JJP, Micheli LJ, Arslanian LE, Kennedy J, Kennedy R: Pattern of flexibility, laxity, and strength in normal shoulders and shoulders with instabilityand impingement. American Journal of Sports Medicine 1990, 18:366-375

82. TaheriAzam A, Sadatsafavi M, Moayyeri A: Outcome predictors in nonoperative management of newly diagnosed subacromial impingmeent syndrome: a longitudinal study. Medscape General Medicine 2005, 7:63.

83. Kuijpers T, van der Windt DAWM, van der Heijden GJMG, Bouter LM Systematic review of prognostic cohort studies on shoulder disorders. Pain 2004, 109:420-431.

84. Kuijpers T, van der Windt DAWM, Boeke AJP, Twisk JWR, Vergouwe Y, Bouter LM, van der Heijden GJMG: Clincal presentation for the prognosis of shoulder pain in general practice. Pain 2006, 120:276-285.

85. Habermayer $P$, Lehmann L, Lichtenberg S: RotatorenmanschettenRuptur. Orthopäde 2000, 29:196-208.

86. Smith KL, Harryman DT II, Antonlou J, Campbell B, Sidles JA, Matsen FA III: A prospective, multipractice study of shoulder function and health status in patients with documented rotator cuff tears. Journal of Shoulder and Elbow Surgery 2000, 9:395-402.

87. Pope DP, Croft PR, Pritchard CM, MCFarlane GJ, Silman AJ: The frequency of restricted range of movement in individuals with self-reported shoulder pain: results from a population-based survey. British Journal of Rheumatology 1996, 35:1137-1141

88. Kaltenborn F: Manuelle Mobilisation der Extremitätengelenke. Oslo: Olaf Noris Bokhandel; 1992.

89. Jones MA, Rivett DA: Clinical Reasoning for Manual Therapists. Butterworth-Heinemann; 2004

90. MacDermid J, Solomon P, Prkachin K: The shoulder pain and disability index dmonstrates factor, construct and longitudinal validity. $B M C$ Musculoskeletal Disorders 2006, 7:12.

91. Beaton DE, Richards RR: Measuring function of the shoulder. A crosssectional comparison of five questionnaires. Journal of Bone and Joint Surgery 1996, 78A:882-890.

92. Cloke DJ, Lynn SE, Watson H, Steen IN, Purdy S, Williams JR: A comparison of functional, patient-based scores in subacromial impingement. Journal of Shoulder and Elbow Surgery 2005, 14:380-384.

93. Williams JW, Holleman DR, Simel DL: Measuring shoulder function with the shoulder pain and disability index. Journal of Rheumatology 1995, 22:727-732.

94. ten Klooster PM, Drossaers-Bakker KW, Taal E, van de Laar MAFJ: Patientperceived satisfactory improvement (PPSI): Interpreting meaningful change in pain from the patient's perspective. Pain 2006, 121:151-157. 
95. Farrar JT, Young JP Jr, LaMoreaux L, Werth JL, Poole RM: Clinical importance of changes in chronic pain intensity measured on an 11point numerical pain rating scale. Pain 2001, 94:149-158.

96. Stratford PW, Gill C, Westaway MD, Binkley JM: Assessing disability and change on individual patients: a report of a patient specific measure. Physiotherapy Canada 1995, 47:258-263.

97. Donnelly C, Carswell A: Individualized outcome measures: a review of the literature. Revue Canadienne D'Ergothèrapie 2002:84-94

98. Chatman AB, Hyams SP, Neel JM, Binkley JM, Stratford PW, Schomberg A Stabler M: The Patient-Specific Functional Scale: Measurement properties in patients with knee function. Physical Therapy 1997 77:820-829

99. Westaway MD, Stratford PW, Binkley JM: The patient-specific functional scale: validation of its use in persons with neck dysfunction. Journal of Orthopaedic and Sports Physical Therapy 1998, 27:331-338.

100. Salaffi F, Stancati A, Silvestri CA, Ciapetti A, Grassi W: Minimal clinically important changes in chronic musculoskeletal pain intensity measured on a numerical rating scale. European Journal of Pain 2004, 8:283-291.

101. Waddell G, Newton M, Henderson I, Somerville D, Main CJ: A fearavoidance beliefs questionnaire (FABQ) and the role of fear-avoidance beliefs in chronic low-back pain and disability. Pain 1993, 52:157-168.

102. Pfingsten M, Kröner-Herwig B, Leibing E, Kronshage U, Hildebrandt J: Validation of the German version of the Fear-Avoidance Beliefs Questionnaire (FABQ). European Journal of Pain 2000:4259-266.

103. Staerkle R, Mannion AF, Elfering A, Junge A, Semmer NK, Jacobshagen N, Grob D, Dvorak J, Boos N: Longitudinal validation of the Fear-Avoidance Beliefs Questionnaire (FABQ) in a Swiss-German sample of low back pain patients. European Spine Journal 2004, 13:332-340.

104. Crombez G, Vlaeyen JWS, Heuts PHTG, Lysens R: Pain-related fear is more disabling than pain itself: evidence on the role of pain-related fear in chronic back pain disability. Pain 1999, 80:329-339.

105. Swinkels-Meewisse EJCM, Swinkels RAHM, Verbeek ALM, Vlaeyenz JWS, Oostendorp RAB: Psychometric properties of the Tampa scale for kinesiophobia and the fear-avoidance beliefs questionnaire in acute low back pain. Manual Therapy 2003, 8:29-36.

106. Osman A, Barrios FX, Kopper BA, Hauptmann W, Jones J, O'Neill E: Factor structure, reliability, and validity of the pain catastrophizing scale. Journal of Behavioral Medicine 1997, 20:589-605

107. Weissman-Fogel I, Sprecher E, Pud D: Effects of catastrophizing on pain perception and pain modulation. Eperimental Brain Research 2008, 186:79-85.

108. Block CK, Brock J: The relationship of pain catastrophizing to heightened feelings of distress. Pain Management Nursing 2008, 9:73-80.

109. Osman A, Barrios FX, Guittierrez PM, Kopper BA, Merrifield T, Grittmann L: The pain catastrophizing Ssale: further psychometric evaluation with adult samples. Journal of Behavioral Medicine 2000, 23:351-365.

110. Sullivan MJ, Bishop SR, Pivik J: The pain catastrophizing scale: development and validation. Psychological Assessment 1995, 7:524-532.

111. Meyer K, Sprott H, Mannion AF: Cross-cultural adaptation, reliability, and validity of the German version of the pain catastrophizing scale. Journal of Psychosomatic Research 2008, 64:469-478.

112. Sullivan MJ, Stanish W, Waite H, Sullivan M, Tripp DA: Catastrophizing, pain, and disability in patients with soft-tissue injuries. Pain 1998, 77:253-260

113. Lame I, Peters ML, Kessels AG, van Kleef M, Patijn J: Test-retest stability of the pain catastrophizing scale and the tampa scale for kinesiophobia in chronic pain patients over a longer period of time. Journal of Health Psychology 2008, 13:820-826.

114. Goossens MEJB, Vlaeyen JWS, Hidding A, Kole-Snijders A, Evers SMAA: Treatment expectancy affects the outcome of cognitive-behavioral interventions in chronic pain. Clinical Journal of Pain 2005, 21:18-26.

115. Smeets RJEM, Beelen S, Goossens MEJB, Schouten EGWJ, Knottnerus A, Vlaeyen JWS: Treatment expectancy and credibility are associated with the outcome of both physical and cognitive-behavioral treatment in chronic low back pain. Clinical Journal of Pain 2008, 24:305-315.

116. Deviliya GJ, Borkovecb TD: Psychometric properties of the credibility/ expectancy questionnaire. Journal of Behavior Therapy \& Experimental Psychatry 2000, 31:73-86.

117. Carette S, Moffet H, Tardif J, Bessette L, Morin F, Fremont P, Bykerk V, Thorne C, Bell M, Bensen W, Blanchette C: Intraarticular corticosteroids, supervised physiotherapy, or a combination of the two in the treatment of adhesive capsulitis of the shoulder. Arhtitis \& Rheumatism 2003, 48:829-838.

118. Chen JF, Ginn KA, Herbert RD: Passive mobilisation of shoulder region joints plus advice and exercise does not reduce pain and disability more than advice and exercise alone: a randomised trial. Australian Journal of Physiotherapy 2009, 55:17-23.

119. Dogru H, Basaran S, Tunay S: Effectiveness of therapeutic ultrasound in adhesive capsulitis. Joint Bone Spine 2008, 75:445-450.

120. Tveita EK, Tariq R, Sesseng S, Juel NG, Bautz-Holter E: Hydrodilatation, cortocosteroids and adhesive capsulitis: a randomized controlled trial. BMC Musculoskeletal Disorders 2008, 9:53.

\section{Pre-publication history}

The pre-publication history for this paper can be accessed here: http://www.biomedcentral.com/1471-2474/11/114/prepub

doi: $10.1186 / 1471-2474-11-114$

Cite this article as: Kromer et al., Effectiveness of individualized physiotherapy on pain and functioning compared to a standard exercise protocol in patients presenting with clinical signs of subacromial impingement syndrome. A randomized controlled trial BMC Musculoskeletal Disorders 2010, $11: 114$

\section{Submit your next manuscript to BioMed Centra} and take full advantage of:

- Convenient online submission

- Thorough peer review

- No space constraints or color figure charges

- Immediate publication on acceptance

- Inclusion in PubMed, CAS, Scopus and Google Scholar

- Research which is freely available for redistribution

Submit your manuscript at www.biomedcentral.com/submit
C) Biomed Central 